\title{
Overexpression of PAD4 suppresses drug resistance of NSCLC cell lines to gefitinib through inhibiting Elk1-mediated epithelial-mesenchymal transition
}

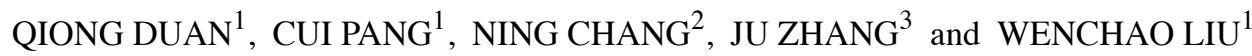 \\ Departments of ${ }^{1}$ Oncology and ${ }^{2}$ Respiratory Medicine, Xijing Hospital, The Fourth Military Medical University, Xi'an, \\ Shaanxi 710032; ${ }^{3}$ Institute of Gene Diagnosis, State Key Laboratory of Cancer Biology, School of Pharmacology, \\ The Fourth Military Medical University, Xi'an, Shaanxi 710032, P.R. China
}

Received December 30, 2015; Accepted February 11, 2016

DOI: $10.3892 /$ or.2016.4780

\begin{abstract}
It is reported that epithelial-to-mesenchymal transition (EMT) could induce resistance in tumor cells, and knockdown of peptidylarginine deiminase IV (PAD4) induces the activity of EMT. However, the role of PAD4 in gefitinib-acquired resistance in non-small cell lung cancer (NSCLC) remains unclear. In this study, we aimed to investigate the role of PAD4 in the resistance of NSCLC to gefitinib. The cells resistant to gefitinib were established in accordance with the literature, and were derived from NSCLC cell lines HCC827 and H1650. Real-time quantitative PCR and western blot results showed that PAD4 was obviously downregulated in the cells resistant to gefitinib. Overexpression of PAD4 distinctly inhibited gefitinib resistance, whereas PAD4 downregulation had the opposite effect. Further data indicated that PAD4 upregulation could restrain EMT activity via control-
\end{abstract}

Correspondence to: Dr Ju Zhang, Institute of Gene Diagnosis, State Key Laboratory of Cancer Biology, School of Pharmacology, The Fourth Military Medical University, 169 West Changle Road, Xi'an, Shaanxi 710032, P.R. China

E-mail: juzhangfire@sina.com

Dr Wenchao Liu, Department of Oncology, Xijing Hospital, The Fourth Military Medical University, 15 West Changle Road, Xi'an, Shaanxi 710032, P.R. China

E-mail: wenchaoliuwcl@163.com

Abbreviations: EMT, epithelial-to-mesenchymal transition; PAD4, peptidylarginine deiminase IV; NSCLC, non-small cell lung cancer; TKI, tyrosine kinase inhibitors; EGFR, epidermal growth factor receptor; RA, rheumatoid arthritis; MTT, 3-(4,5-dimethyl thiazol-2-yl)-2,5-diphenyltetrazolium bromide; DMSO, dimethyl sulfoxide; Annexin V-FITC/PI, Annexin V-fluorescein isothiocyanate/propidium iodide; GAPDH, glyceraldehyde-3-phosphate dehydrogenase; PMSF, phenylmethanesulfonyl fluoride; SDS-PAGE, sodium dodecyl sulfate-polyacrylamide gel electrophoresis

Key words: Elk1, epithelial-to-mesenchymal transition, gefitinib, non-small cell lung cancer, PAD4, resistance ling the expression of ETS-domain containing protein (Elk1). Conversely, inhibition of PAD4 showed the reverse function compared with PAD4 upregulation. Above all, our study showed that overexpression of PAD4 constrains the activity of EMT via suppressing Elk1 expression, and inhibits resistance of NSCLC to gefitinib.

\section{Introduction}

Lung cancer is the world's most common cause of cancer fatality, accounting for $1 / 3$ of tumor causes $(1,2)$. In recent years, lung cancer cases in China showed a rapid growth trend. A total of $80 \%$ of lung cancer fatalities are due to non-small cell lung cancer (NSCLC) (3-5). However, traditional chemotherapy treatment programs are not optimal for NSCLC. Currently, molecular targeted drugs are widely used in the treatment of advanced NSCLC because of their high specificity, significant therapeutic effects and minimal side effects.

With the in-depth studies of the molecular mechanisms of lung cancer in recent years, tremendous progress has been made regarding the treatment of advanced NSCLC by tyrosine kinase inhibitors (TKI) which target the epidermal growth factor receptor (EGFR) (6-9). As the main drug within EGFR-TKIs, gefitinib is one of the first drugs used in the treatment of NSCLC (10-12). However, many patients taking gefitinib will develop drug resistance. Currently, the T790M mutation and c-MET gene amplification are the main accepted reasons for this resistance (13). It is also reported that epithelial-mesenchymal transition (EMT) of tumor cells (14), which can cause drug resistance in lung cancer, is thought to be inhibited by histone deacetylase inhibitors, but the effect of histone deacetylase inhibitors is still uncertain (15). In our study, we investigated the resistance mechanism of EMT and provided a basis for the study of NSCLC resistance to gefitinib.

It is known that peptidylarginine deiminase IV (PAD4) downregulation induces EMT (16). Therefore, we hypothesized that overexpression of PAD4 could inhibit EMT and thus suppress drug resistance. Peptidylarginine deiminase IV is a nuclear enzyme that converts histone arginine residues to citrulline at apoptosis-related gene promoters and represses gene expression, amongst other functions $(16,17)$. In recent 
years, studies have indicated that PAD4 is related to many diseases, such as rheumatoid arthritis, cancer, ankylosing spondylitis, and Alzheimer's disease $(16,18)$. Studies have shown that PAD4 is increased in cancer patients and possibly contributes to tumorigenesis (18). However, it is not clear if PAD4 plays a role in the resistance mechanism of NSCLC to gefitinib.

ETS-domain containing protein (Elk1), a transcription factor belonging to the ETS oncogene family, can be phosphorylated by the MAPK cascade (19), and is a regulated factor of oncogene c-fos (20). Additionally, Elk1 is relevant to cell differentiation, proliferation, apoptosis and tumorigenesis (21). It may be an important part of the development of malignant tumors and cell invasion. It has been reported to be involved in the regulation of EMT in osteosarcoma (22). Studies have also revealed that PAD4 deiminates Elk1, and this post-translational modification has a bearing on the phosphorylation of Elk1 (23). However, the possibility that PAD4 can regulate Elk1 has not yet been confirmed. For this reason, we hypothesized that PAD4 regulates EMT through controlling the expression of Elk1.

Epithelial-mesenchymal transition is a process where epithelial cells become mesenchymal cells (24). In this process, epithelial markers such as E-cadherin and $\alpha$-catenin are reduced, and mesenchymal markers such as $\mathrm{N}$-cadherin and vimentin are upregulated $(25,26)$. Epithelial-mesenchymal transition is not only involved in embryonic development and normal physiology, but is also involved in many pathologic processes. Additionally, increasing evidence has demonstrated that EMT plays a role in tumorigenesis, and the development and migration of tumor cells (27). The resistance to gefitinib in NSCLC cell lines has been reported be related to EMT. Non-small cell lung cancer lines that had undergone EMT obtained resistance to the growth inhibitory effects of EGFR-TKIs such as gefitinib, both in vitro and in xenografts (14).

In this study, we investigated the molecular mechanism of PAD4 in the resistance of NSCLC to gefitinib. We found that overexpression of PAD4 could inhibit EMT and the resistance to gefitinib. Further analysis showed that PAD4 could suppress resistance by inhibiting Elk1 expression. Peptidylarginine deiminase IV may thus be a promising molecular target for treatment of the resistance of NSCLC to gefitinib.

\section{Materials and methods}

Establishment of the NSCLC cell lines resistant to gefitinib. The curative effect of gefitinib is closely related to EGFR mutations such as the deletion mutation of exon-19. The NSCLC cell lines HCC827 and H1650, which contain the deletion mutation of exon-19, were purchased from the American Type Culture Collection (ATCC; Manassas, VA, USA), and the established method was in accordance with Engelman et al (28). The cell lines HCC827/G, H1650/G resistant to gefitinib and NSCLC cell lines HCC827 and H1650 were cultured in RPMI-1640 medium (Hyclone, Salt Lake City, UT, USA) with $10 \%$ fetal bovine serum (FBS; Gibco, Rockville, MD, USA), penicillin and streptomycin (100 U/ml and $100 \mathrm{mg} / \mathrm{ml}$, respectively; Gibco) in an atmosphere of $5 \% \mathrm{CO}_{2}$ at $37^{\circ} \mathrm{C}$.
Cell growth and viability. The cell growth and viability were measured by 3-(4,5-dimethylthiazol-2-yl)-2,5-diphenyltetrazolium bromide (MTT) assay based on the manufacturer's instructions. In brief, the cells were plated in the 96-well plate and the density was $1 \times 10^{4}$ cells/well. Then, MTT was diluted in phosphate buffered saline to $5 \mathrm{~g} / \mathrm{l}$, and $20 \mu \mathrm{l}$ was added to each well to replace the culture medium. Thereafter, the 96 -well plate was stored at $37^{\circ} \mathrm{C}$ for $4 \mathrm{~h}$. Subsequently, dimethyl sulfoxide (DMSO) was added (150 $\mu \mathrm{l} /$ well) in the plate to dissolve the crystals. Ultimately, absorbance was detected by the microplate reader at $490 \mathrm{~nm}$ (Thermo Fisher Scientific, Waltham, MA, USA).

Annexin V-FITC/PI. Annexin V-fluorescein isothiocyanate (FITC)/propidium iodide (PI) apoptosis detection kit (Invitrogen, Carlsbad, CA, USA) was used according to the manufacturer's instructions to identify cell apoptosis. Cells were suspended in binding buffer, $10 \mu \mathrm{l}$ of Annexin V-FITC solution was added, and they were incubated at $4^{\circ} \mathrm{C}$ for 25 min. Next, cells were washed with PBS, $10 \mu 1$ of PI was added, and they were incubated for $5 \mathrm{~min}$. Cellular apoptosis was measured by a FACS analyzer (Thermo Fisher Scientific, Waltham, MA, USA).

Construction of $p C M V-2 a / 2 b-P A D 4$ and $p C M V-2 a / 2 b-E l k 1$. The full-length cDNA of PAD4 (accession no. NM_012387) and Elk1 (accession no. AB016194.1) were both amplified by reverse transcription PCR, and then cloned into the pCMV-2a/2b vector (Novagen, Madison, WI, USA). The restriction sites included EcoRI and BamHI in the amplified cDNA and pCMV-2a/2b vector. Next, the two different recombinant plasmids were separately transformed into DH5 $\alpha$ competent cells (Takara Biotechnology, Dalian, China), and the transformed DH5 $\alpha$ was grown overnight at $37^{\circ} \mathrm{C}$. Plasmids were extracted and then sequenced to identify the correct ones. The correct plasmids were named as pCMV-2a/2b-PAD4 and pCMV-2a/2b-Elk1.

Transfection of the recombinant plasmids and siRNA. HCC $827 / \mathrm{G}$ and H1650/G (5x104/well) were separately plated in the 24-well plate and incubated in a humidified atmosphere containing $5 \% \mathrm{CO}_{2}$ at $37^{\circ} \mathrm{C}$ for $24 \mathrm{~h}$ followed by the transfection strictly according to the manufacturer's instruction. A total of $3 \mu \mathrm{l}$ TurboFect (Thermo Fisher Scientific) was separately added to the recombinant plasmids (pCMV-2a/2b-PAD4, pCMV-2a/2b-Elk1or pCMV-2a/2b), PAD4 siRNA (5'-GCGAAGACCTGCAGGACAT-3') or non-specific siRNA with $100 \mu 1$ serum-free RPMI-1640 medium, and the mixtures were each added to the wells. Finally, the plate was placed in the incubator (Thermo Fisher Scientific) with $5 \% \mathrm{CO}_{2}$ at $37^{\circ} \mathrm{C}$ for another $24 \mathrm{~h}$.

Quantitative real-time polymerase chain reaction ( $q R T-P C R$ ). TRIzol reagent (Takara Biotechnology) was used to extract the total RNA from the cells with the different treatments. A total of $6 \mu \mathrm{g}$ of the extracted RNA was synthesized into the cDNA that would be used as the template in the qRT-PCR. Additionally, the synthesis process of the cDNA was in terms of the reverse transcription kit (Invitrogen). A volume of $10 \mu \mathrm{l}$ SsoFast $^{\mathrm{TM}}$ EvaGreen Supermix (Bio-Rad, Hercules, CA, USA) 
Table I. The primers of qRT-PCR.

\begin{tabular}{|c|c|}
\hline $\begin{array}{l}\text { Gene } \\
\text { names }\end{array}$ & Primer sequences \\
\hline PAD4 & $\begin{array}{l}\text { Sense: 5'-GGACTGCGAGGATGATG-3' } \\
\text { Anti-sense: 5'-GCTGTCTTGGAACACCAC-3' }\end{array}$ \\
\hline Elk1 & $\begin{array}{l}\text { Sense: 5'-CCTTGCGGTACTACTATGAC-3' } \\
\text { Anti-sense: 5'-GGCTGCGGCTGCAGAGACTGG-3' }\end{array}$ \\
\hline E-cadherin & $\begin{array}{l}\text { Sense: 5'-TACACTGCCCAGGAGCCAGA-3' } \\
\text { Anti-sense: 5'-TGGCACCAGTGTCCGGATTA-3' }\end{array}$ \\
\hline$\alpha$-catenin & $\begin{array}{l}\text { Sense: 5'-CTCTACTGCCACCAGCTGAACATC-3' } \\
\text { Anti-sense: 5'-ATGCCTTCACTGTCTGCACCAC-3' }\end{array}$ \\
\hline $\mathrm{N}$-cadherin & $\begin{array}{l}\text { Sense: 5'-CGAATGGATGAAAGACCCATCC-3' } \\
\text { Anti-sense: 5'-TAGCAGCTTCAACGGCAAAGTTC-3 }\end{array}$ \\
\hline Vimentin & $\begin{array}{l}\text { Sense: 5'-TGAGTACCGGAGACAGGTGCAG-3' } \\
\text { Anti-sense: 5'-GGAGCCACTGCCTTCATAGTCAA-3' }\end{array}$ \\
\hline GAPDH & $\begin{array}{l}\text { Sense: 5'-CGTCTTCACCACCATGGAGA-3' } \\
\text { Anti-sense: 5'-CGGCCATCACGCCACAGTTT-3' }\end{array}$ \\
\hline
\end{tabular}

was added into $20-\mu 1$ reactive volume in the qRT-PCR. The qRT-PCR protocol was as follows: $95^{\circ} \mathrm{C}$ for $20 \mathrm{sec} ; 35$ cycles of denaturation at $95^{\circ} \mathrm{C}$ for $30 \mathrm{sec}$, annealing at $52^{\circ} \mathrm{C}(\mathrm{Elk} 1)$, $58^{\circ} \mathrm{C}$ [PAD4, glyceraldehyde-3-phosphate dehydrogenase $(\mathrm{GAPDH})]$ or $60^{\circ} \mathrm{C}$ (E-cadherin, $\alpha$-catenin, vimentin and $\mathrm{N}$-cadherin) for $20 \mathrm{sec}$ and extension at $72^{\circ} \mathrm{C}$ for $30 \mathrm{sec}$. The data obtained were calculated by $2^{-\Delta \Delta \mathrm{Ct}}$ and the target gene relative expression levels were normalized to GAPDH. The primers are presented in Table I.

Western blot analysis. The proteins were extracted from the cells using lysis buffer with phenylmethanesulfonyl fluoride (PMSF) for $30 \mathrm{~min}$ on ice, and the concentrations of the proteins were measured by the BCA kit (Pierce, Rockford, IL, USA). Twenty-five micrograms of protein was loaded in $12 \%$ sodium dodecyl sulfate-polyacrylamide gel electrophoresis (SDS-PAGE) and transferred by a semi-dry blotting apparatus (Bio-Rad). Blots were washed with Tris buffered saline with Tween (TBST), and then blocked using 5\% skim milk in Tris buffered saline for $2 \mathrm{~h}$. Next, blots were incubated with the primary antibodies (Cell Signaling Technology, Danvers, MA, USA), diluted (1:500) in the blocking buffer at $4^{\circ} \mathrm{C}$ overnight, incubated in the horseradish peroxidase-conjugated secondary antibody (Abcam, Cambridge, UK) and diluted $(1: 1,000)$ in the blocking buffer at room temperature for $1 \mathrm{~h}$. Blots were analyzed in the Bio-Rad ChemiDoc apparatus.

Statistical analysis. The differences were determined by Student's t-test for two groups or by one-way ANOVA followed by Bonferroni's test for multiple groups. A $\mathrm{P}<0.05$ was recognized as statistically significant. Data were processed as mean \pm standard deviation (SD).

\section{Results}

Demonstration of the drug resistance of cell lines to gefitinib and the protein expression of PAD4. Drug resistance was demonstrated using the Annexin V-FITC/PI apoptosis
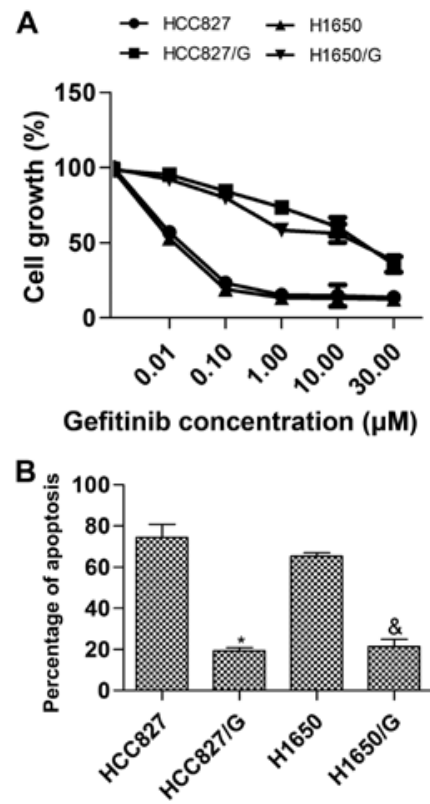

Figure 1. Drug resistance of cell lines to gefitinib. (A) The percent survival of cell lines was measured by MTT assay following culture with increasing concentrations of gefitinib for $72 \mathrm{~h}$. (B) Cell lines were treated with $1 \mu \mathrm{mol} / 1$ gefitinib for $72 \mathrm{~h}$, and the apoptosis of cell lines was detected by Annexin V-FITC/PI assay. $\mathrm{n}=6,{ }^{*} \mathrm{P}<0.05$ for the HCC827/G cell line vs. the HCC827 cell line; ${ }^{\circledR} \mathrm{P}<0.05$ for the H1650/G cell line vs. the H1650 cell line.

detection kit and MTT assay. The detections were performed following the cell treatments. The treated cells were cultured in $180 \mu \mathrm{l}$ RPMI-1640 medium containing $10 \%$ FBS and $20 \mu \mathrm{l}$ of various concentrations of gefitinib for $72 \mathrm{~h}$ at $37^{\circ} \mathrm{C}$. In the MTT assay, the percent survival (Fig. 1A) was calculated as: (mean absorbance of six replicate wells containing drugs mean absorbance of six replicate background wells)/(mean absorbance of six replicate drug-free wells - mean absorbance of six replicate background wells) $\mathrm{x} 100$. The results showed that the half maximal inhibitory concentration $\left(\mathrm{IC}_{50}\right)$ of $\mathrm{HCC} 827 / \mathrm{G}$ and $\mathrm{H} 1650 / \mathrm{G}$ cell lines were $16.5 \pm 6.3$ and $14.1 \pm 3.7 \mu \mathrm{mol} / 1$, respectively, and the $\mathrm{IC}_{50}$ of $\mathrm{HCC} 827$ and $\mathrm{H} 1650$ cell lines were $0.03 \pm 0.02$ and $0.02 \pm 0.01 \mu \mathrm{mol} / 1$, respectively. The drug resistance of $\mathrm{HCC} 827 / \mathrm{G}$ or $\mathrm{H} 1650 / \mathrm{G}$ was significantly higher than that of HCC827 or H1650 (P<0.01). In the Annexin V-FITC/PI apoptosis detection assay, the cells cultured with $1 \mu \mathrm{mol} / 1$ gefitinib were measured, and the results indicated that the apoptosis induced by gefitinib in HCC827/G or H1650/G was lower than that in HCC827 or H1650, respectively (Fig. 1B). In conclusion, the establishment of drug resistant cell lines to gefitinib was successful. Additionally, the relative protein expression of PAD4 in HCC827/G or H1650/G was distinctly reduced compared with $\mathrm{HCC} 827$ or H1650 (Fig. 2).

Overexpression of PAD4 suppresses drug resistance to gefitinib. To investigate the influence of PAD4 expression changes on the drug resistance of NSCLC cell lines to gefitinib, we promoted and inhibited the expression of PAD4, and cultured the cells with $1 \mu \mathrm{mol} / 1$ of gefitinib. The detection showed that the mRNA (Fig. 3A) and protein (Fig. 3B-D) expression levels of PAD4 in the PAD4 siRNA transfected group were significantly lower than in the non-specific siRNA transfected group. The mRNA (Fig. 3A) and protein (Fig. 3B-D) 


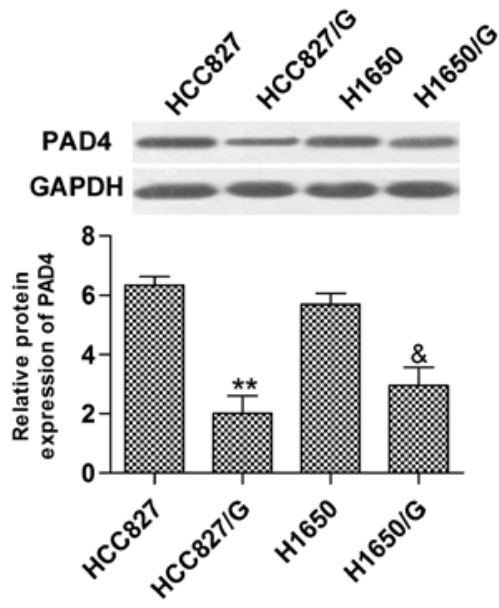

Figure 2. PAD4 expression after the treatment of gefitinib. Relative protein expression of PAD4 was detected by western blot analysis. The GAPDH was used as the control. $n=3,{ }^{* *} \mathrm{P}<0.01$ for the HCC $827 / \mathrm{G}$ cell line vs. the HCC827 cell line; ${ }^{\mathrm{P}}<0.05$ for the $\mathrm{H} 1650 / \mathrm{G}$ cell line vs. the $\mathrm{H} 1650$ cell line.

expression levels of PAD4 in the pCMV-2a/2b-PAD4 transfected group were significantly upregulated contrasting with the $\mathrm{pCMV}-2 \mathrm{a} / 2 \mathrm{~b}$ transfected group. Subsequently, the effect of PAD4 overexpression or inhibition on drug resistance was measured by MTT assay and Annexin V-FITC/PI apoptosis detection. In the MTT assay, the cell growth and viability of the pCMV-2a/2b-PAD4 transfected group was obviously decreased in contrast with the $\mathrm{pCMV}-2 \mathrm{a} / 2 \mathrm{~b}$ transfected group (Fig. 4A). Conversely, inhibition of PAD4 by transfection of PAD4 siRNA exhibited the opposite effect (Fig. 4A). Moreover, in the Annexin V-FITC/PI apoptosis detection, pCMV-2a/2b-PAD4 transfection induced apoptosis compared with the pCMV-2a/2b transfection (Fig. 4B). Additionally, PAD4 siRNA transfection had the opposite effect of pCMV-2a/2b-PAD4 transfection (Fig. 4B). To summarize, upregulation of PAD4 suppressed drug resistance of NSCLC cell lines to gefitinib.

Overexpression of PAD4 constrains Elk1 and EMT. We identified that Elk1 expression and the EMT activity were both inhibited by PAD4 overexpression in the cells cultured with $1 \mu \mathrm{mol} / 1$ of gefitinib. The mRNA (Fig. 5A and D) and protein (Fig. 5B, C, E and F) of Elk1, N-cadherin and vimentin were significantly downregulated by pCMV-2a/2b-PAD4 transfection while E-cadherin and $\alpha$-catenin were upregulated. In addition, PAD4 siRNA transfection had a reverse impact compared with pCMV-2a/2b-PAD4 transfection (Fig. 5).

Overexpression of PAD4 inhibits EMT through suppression of Elk1. We demonstrated that PAD4 overexpression inhibits both EMT and Elk1. Moreover, it has been reported that Elk1 can regulate the process of EMT (22). So we hypothesized that PAD4 upregulation limits EMT by decreasing Elk1 expression. To this end, we overexpressed both Elk1 and PAD4 by transfecting the plasmids pCMV-2a/2b-Elk1 and pCMV-2a/2b-PAD4 and cultured the cells with $1 \mu \mathrm{mol} / 1$ of gefitinib. The results demonstrated that Elk1 and PAD4 were

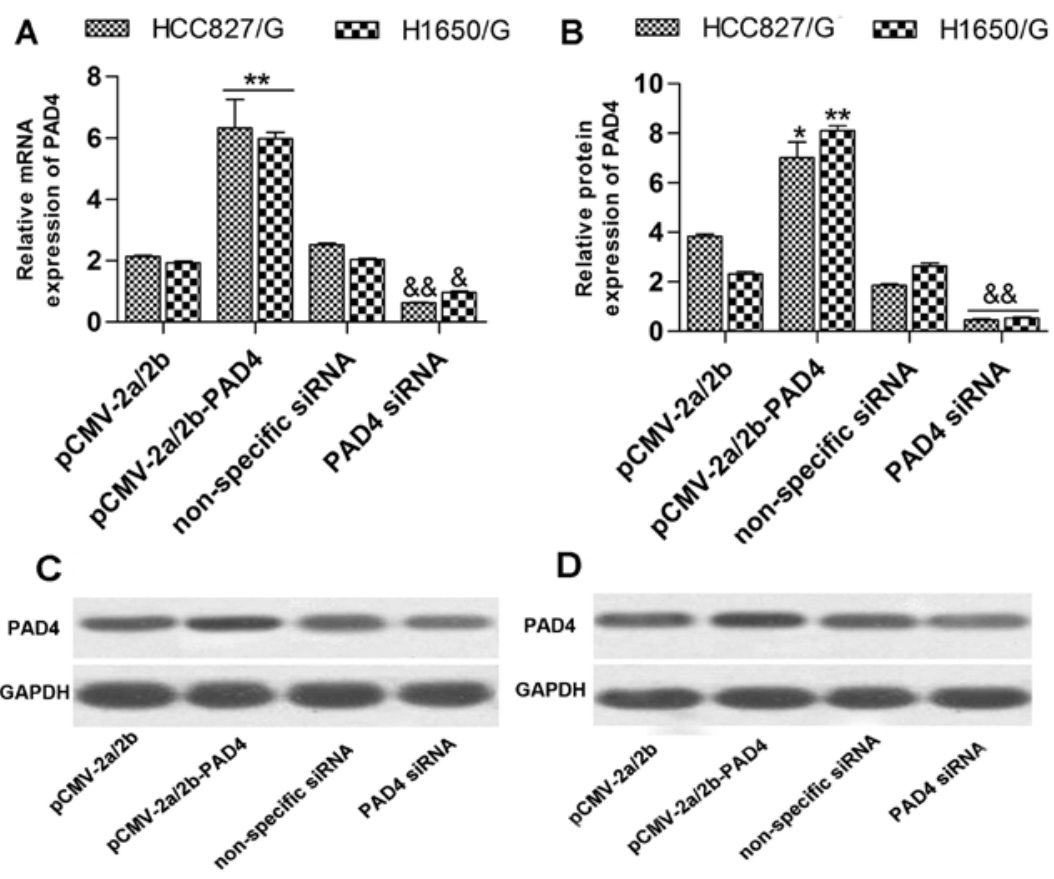

Figure 3. Expression of PAD4 after the transfection. (A) The relative mRNA level of PAD4 was detected by qRT-PCR in HCC827/G and H1650/G cell lines; (B) the relative protein level of PAD4 was measured by western blot analysis in HCC827/G and H1650/G cell lines, and normalized by the GAPDH using Image-Pro Plus 6.0 software. (C) The protein expression level of PAD4 was measured by western blot analysis in HCC827/G. (D) The protein expression level of PAD4 was measured by western blot analysis in H1650/G, pCMV-2a/2b cells transfected with plasmid pCMV-2a/2b, pCMV-2a/2b-PAD4 cells transfected with plasmid pCMV-2a/2b-PAD4, non-specific siRNA cells transfected with non-specific siRNA and PAD4 siRNA cells transfected with PAD4 siRNA. $\mathrm{n}=3$,

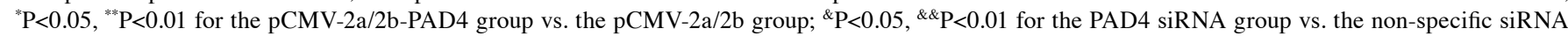
group. 

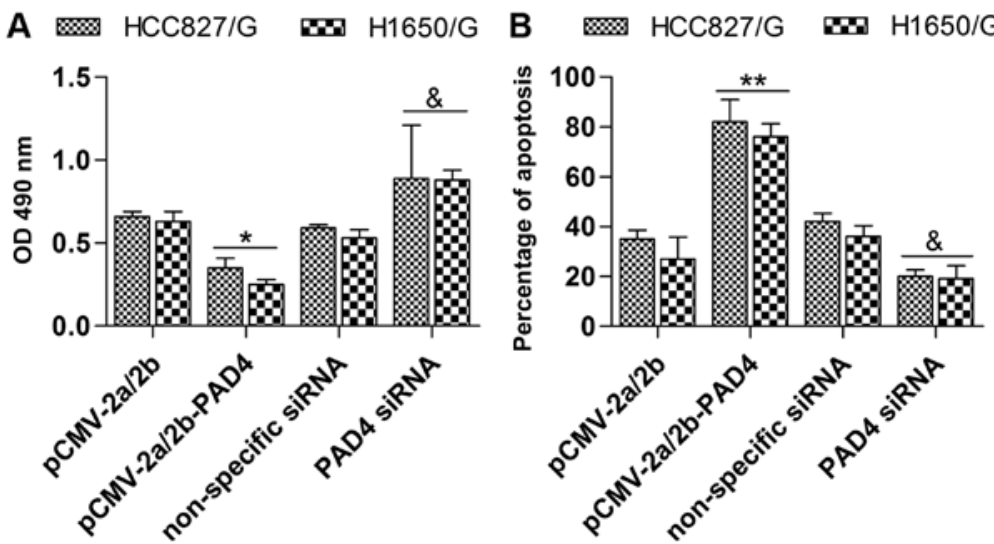

Figure 4. The resistance of cell lines after PAD4 overexpression. (A) Cell growth and viability of HCC827/G and H1650/G cell lines were measured by MTT assay; (B) apoptosis of HCC $827 / \mathrm{G}$ and H1650/G cell lines was detected by Annexin V-FITC/PI assay. $n=6,{ }^{*} \mathrm{P}<0.05,{ }^{* *} \mathrm{P}<0.01$ for the $\mathrm{pCMV}-2 \mathrm{a} / 2 \mathrm{~b}-\mathrm{PAD} 4$ group vs. the $\mathrm{pCMV}-2 \mathrm{a} / 2 \mathrm{~b}$ group; ${ }^{\mathrm{P}} \mathrm{P}<0.05$ for the PAD4 siRNA group vs. the non-specific siRNA group.

A m PAD4 $\quad$ Elk1 $\boxminus$ E-cadherin m $\alpha$-catenin $\mathrm{N}$-cadherin $\mathbf{m}$ Vimentin

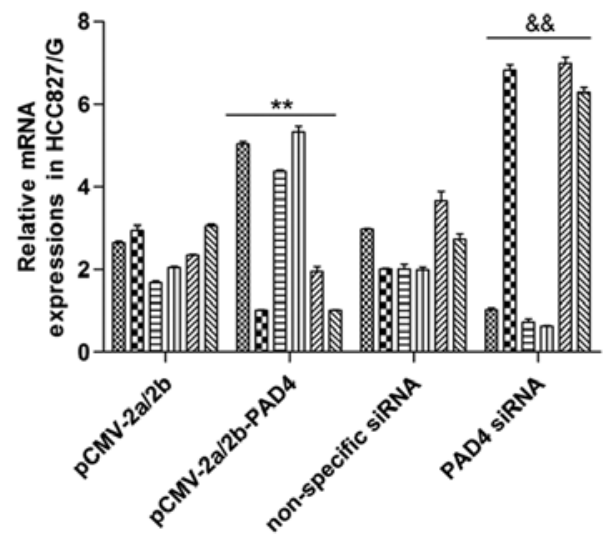

D $\quad$ PAD4 $\quad$ Elk1 $\square$ E-cadherin 띠 $\alpha$-catenin $\mathrm{N}$-cadherin $\mathrm{al}$ Vimentin

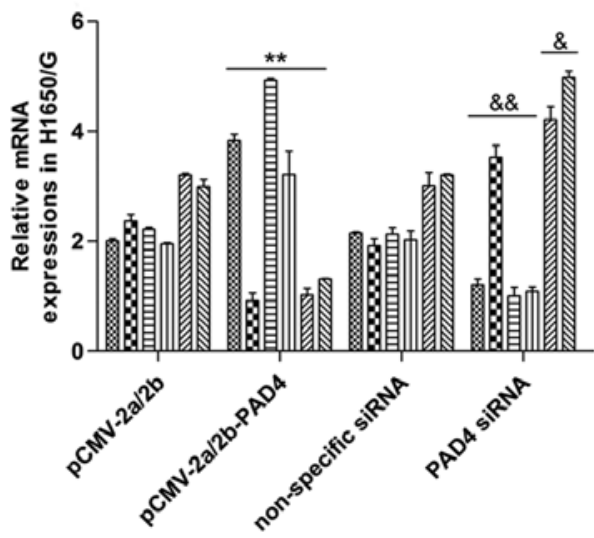

B $\quad$ PAD4 $\quad \mathbf{5 0}$ Elk1 $\square$ E-cadherin

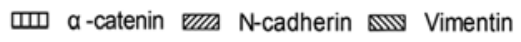

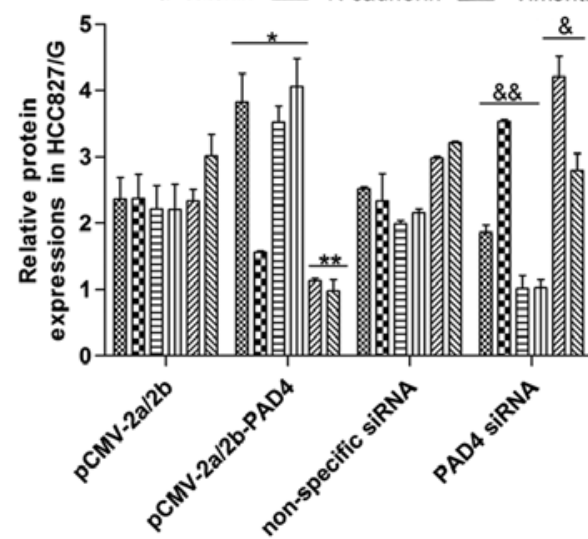

E

․․ PAD4 $\quad$ Elk1 $\boxminus$ E-cadherin

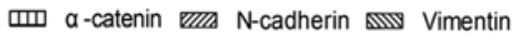

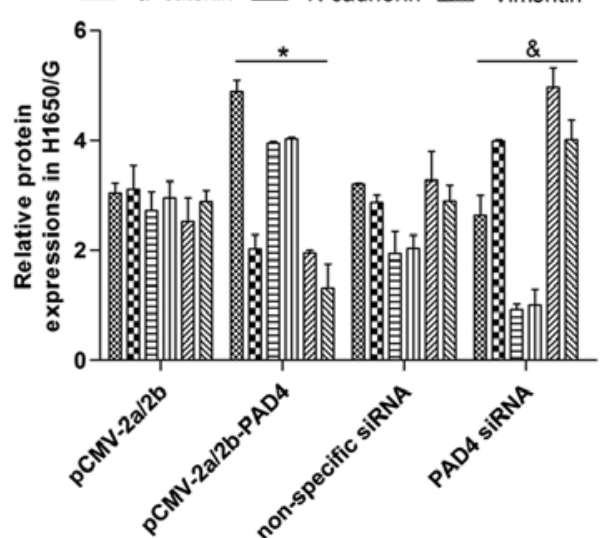

\section{C}
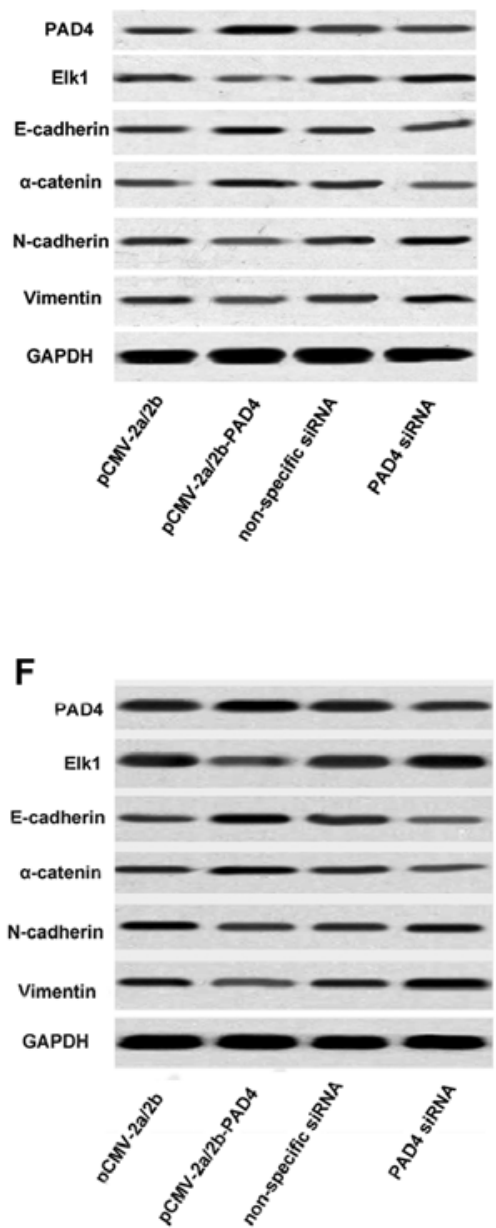

Figure 5. Elk1 expression and EMT activity after PAD4 overexpression. (A and D) The relative mRNA levels of Elk1 and EMT markers were detected by the qRT-PCR in HCC827/G and H1650/G cell lines; (B and E) the relative protein levels of Elk1 and EMT markers were detected by the western blot analysis in HCC827/G and H1650/G cell lines, and quantified using Image-Pro Plus 6.0 software; (C and F) the protein expression levels of Elk1 and EMT markers were detected by the western blot analysis in HCC $827 / \mathrm{G}$ and H1650/G cell lines, separately. $\mathrm{n}=3,{ }^{*} \mathrm{P}<0.05,{ }^{* *} \mathrm{P}<0.01$ for the pCMV-2a/2b-PAD4 group vs. the $\mathrm{pCMV}-2 \mathrm{a} / 2 \mathrm{~b}$ group; ${ }^{\&} \mathrm{P}<0.05,{ }^{\text {\&\&}} \mathrm{P}<0.01$ for the PAD4 siRNA group vs. the non-specific siRNA group.

highly expressed (Fig. 6) and the overexpression of Elk1 apparently reversed the downregulated influence of PAD4 upregulation on EMT (Fig. 6). Furthermore, Elk1 overexpression evidently abolished the drug resistance suppression of
PAD4 overexpression, so the cell growth and viability were distinctly increased compared with PAD4 overexpression only (Fig. 7). Above all, PAD4 overexpression inhibited the drug resistance by controlling the expression of Elk1. 

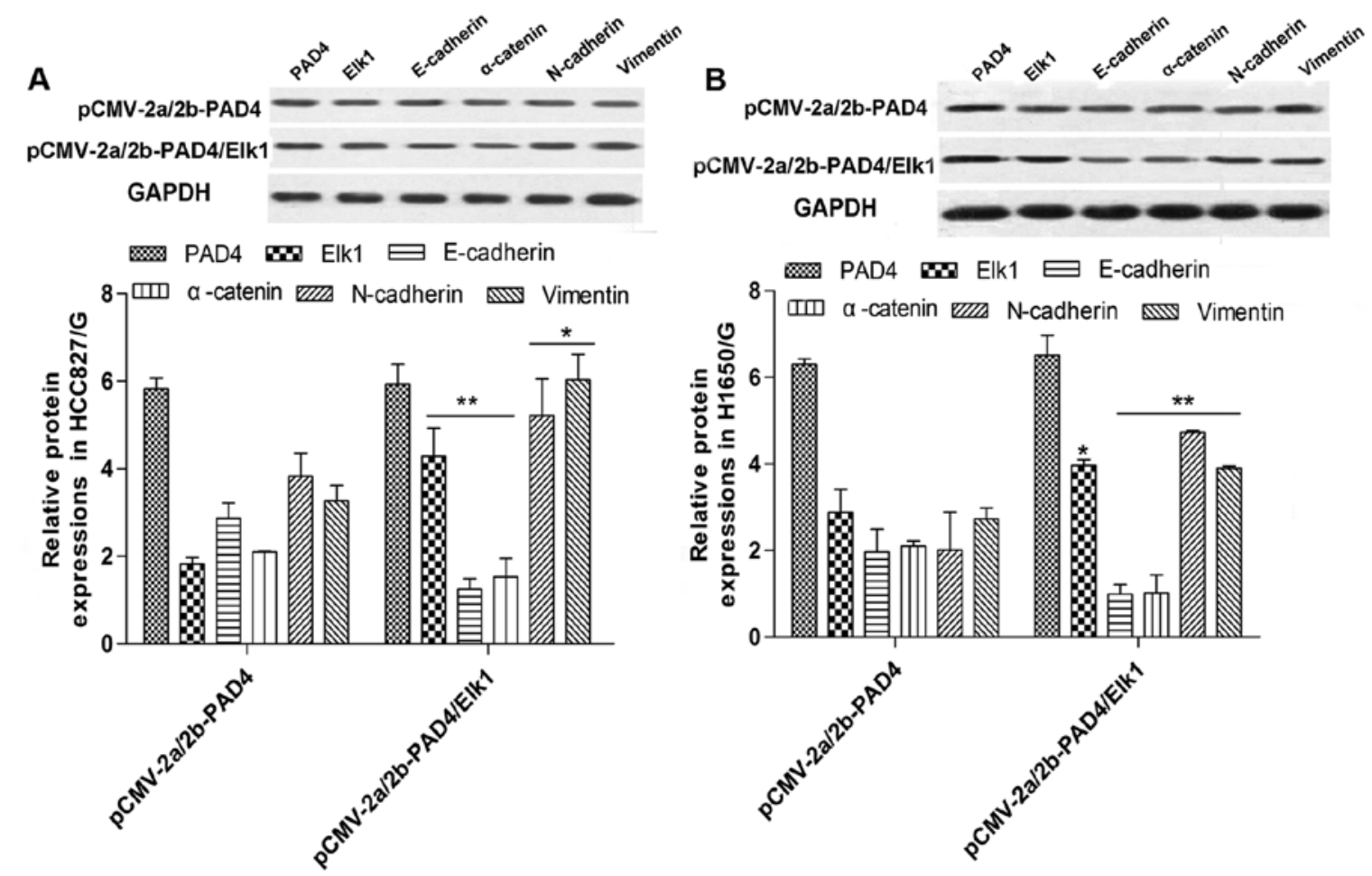

Figure 6. EMT activity after co-expression of PAD4 and Elk1. (A) The relative protein levels of EMT markers were detected by western blot analysis in HCC827/G after the co-expression; (B) the relative protein levels of EMT markers were detected by western blot analysis in H1650/G after the co-expression. pCMV-2a/2b-PAD4/Elk1, cells co-transfected with plasmids pCMV-2a/2b-PAD4 and pCMV-2a/2b-Elk1 n=3, ${ }^{*} \mathrm{P}<0.05,{ }^{* *} \mathrm{P}<0.01$ for the pCMV-2a/2b-PAD4/ Elk1 group vs. the pCMV-2a/2b-PAD4 group.

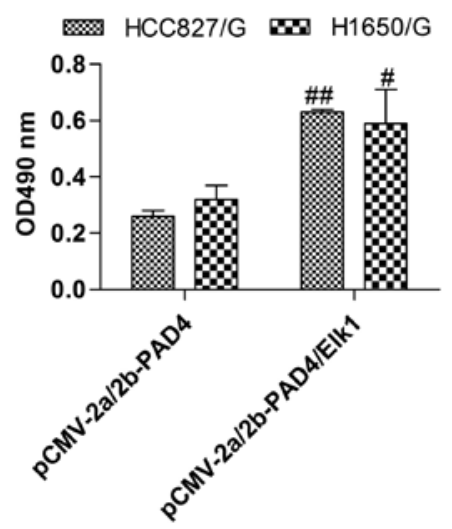

Figure 7. The cell growth and viability after co-expression of PAD4 and Elk1. The cell growth and viability in HCC $827 / \mathrm{G}$ and $\mathrm{H} 1650 / \mathrm{G}$ cell lines were measured by MTT assay. $\mathrm{n}=6,{ }^{\#} \mathrm{P}<0.05,{ }^{\# \#} \mathrm{P}<0.01$ for the pCMV-2a/2bPAD4/Elk1 group vs. pCMV-2a/2b-PAD4 group.

\section{Discussion}

Lung cancer is associated with significant morbidity and mortality, and seriously threatens human health and life (29). In the past 50 years, many countries reported significantly higher lung cancer incidence and mortality rates. Male lung cancer incidence and mortality rates are the highest of all malignant tumors, and female lung cancer is in second place. Non-small cell lung cancer containing glandular cancer, squamous carcinoma and large cell carcinoma comprises $80 \%$ of lung cancer (30-32). Gefitinib (Iressa), is one of the effective drugs for advanced NSCLC. Nevertheless, acquired resistance always appears and puzzles researchers.

Peptidylarginine deiminase IV is a $\mathrm{Ca}^{2+}$-dependent enzyme that converts arginine and methylarginine residues to citrulline (16). It is said that PAD4 helps to regulate immune cell differentiation and cell death (33). Additionally, it plays an important role in many diseases such as rheumatoid arthritis (RA), and it is the main treatment of RA. For breast cancer, inhibition of PAD4 can induce activity of EMT, and EMT is related to the resistance of NSCLC to gefitinib $(14,16)$. In this study, we established the NSCLC cell lines that are resistant to gefitinib according to the literature, and we found that the expression of PAD4 was significantly downregulated in those cells. Next, we constructed the recombinant plasmid pCMV-2a/2b-PAD4, and then transfected the plasmid into the cells, obtaining resistance to gefitinib. The results indicated that the resistance of gefitinib was obviously inhibited following the successful overexpression of PAD4. Moreover, PAD4 siRNA was transfected and the reduction of PAD4 expression had the distinct reverse effect compared with upregulation of PAD4. Other studies demonstrated that PAD4 could act on Elk-1, and Elk1 could influence the process of EMT. However, studies have not determined if PAD4 can regulate Elk1 expression.

Elk1 encodes a related ternary complex factor (TCF) subfamily protein of ETS-domain transcription factors (34). Also, Elk-1 controls the expression of other genes such as oncogene c-fos, smooth muscle-specific genes, and immediate early genes (IEGs) and plays a role in cell apoptosis, proliferation and cancer development $(35,36)$. It was demonstrated 
that Elk1 is upregulated in NSCLC and is nearly undetectable in normal tissue. Therefore, it was speculated that Elk1 probably plays a role in tumorigenesis (37). In our investigation, we found that Elk1 could be regulated by PAD4 in the NSCLC cell lines resistant to gefitinib. Elk1 was distinctly reduced by overexpression of PAD4, whereas it was increased with PAD4 downregulation.

Epithelial-to-mesenchymal transition (EMT) is a basic physiologic and pathologic phenomena involved in embryonic formation and development and tumor invasion and metastasis $(38,39)$. Research findings related to EMT originated from embryonic development studies, whereas in recent years, more are concerned with the study of tumors. Studies have shown that EMT promotes acquired resistance to various apoptotic stimuli (40). In NSCLC treatment, acquired resistance to gefitinib always appears. However, research demonstrated that EMT is induced in gefitinibacquired resistance in lung cancer cells (14). In our study, we found that overexpression of PAD4 obviously inhibited Elk1 and EMT activity, inducing the suppression of resistance to gefitinib. Nevertheless, the co-overexpression of PAD4 and Elk1 promoted EMT, reversing the effect on resistance. Therefore, we confirmed that PAD4 overexpression could suppress the resistance of NSCLC cells to gefitinib.

In summary, this study revealed that upregulation of PAD4 inhibited the resistance of NSCLC to gefitinib through reducing the expression of Elk1. Our study identified the role of PAD4 in gefitinib-acquired resistance in NSCLC, providing a novel target and potential therapeutic strategy to prevent treatment resistance.

\section{Acknowledgements}

This study was supported by grants from the Natural Science Foundation of China (nos. 81371891 and 31170880).

\section{References}

1. Church TR, Black WC, Aberle DR, Berg CD, Clingan KL, Duan F, Fagerstrom RM, Gareen IF, Gierada DS, Jones GC, et al National Lung Screening Trial Research Team: Results of initial low-dose computed tomographic screening for lung cancer. N Engl J Med 368: 1980-1991, 2013.

2. Saghir Z, Dirksen A, Ashraf H, Bach KS, Brodersen J, Clementsen PF, Døssing M, Hansen H, Kofoed KF, Larsen KR, et al: CT screening for lung cancer brings forward early disease. The randomised Danish Lung Cancer Screening Trial: Status after five annual screening rounds with low-dose CT. Thorax 67: 296-301, 2012.

3. Das M, Riess JW, Frankel P, Schwartz E, Bennis R, Hsieh HB, Liu X, Ly JC, Zhou L, Nieva JJ, et al: ERCC1 expression in circulating tumor cells (CTCs) using a novel detection platform correlates with progression-free survival (PFS) in patients with metastatic non-small-cell lung cancer (NSCLC) receiving platinum chemotherapy. Lung Cancer 77: 421-426, 2012.

4. Maemondo M, Minegishi Y, Inoue A, Kobayashi K, Harada M, Okinaga S, Morikawa N, Oizumi S, Tanaka T, Isobe H, et al: First-line gefitinib in patients aged 75 or older with advanced non-small cell lung cancer harboring epidermal growth factor receptor mutations: NEJ 003 study. J Thorac Oncol 7: 1417-1422, 2012.

5. Warth A, Muley T, Meister M, Stenzinger A, Thomas M, Schirmacher P, Schnabel PA, Budczies J, Hoffmann H and Weichert W: The novel histologic International Association for the Study of Lung Cancer/American Thoracic Society/European Respiratory Society classification system of lung adenocarcinoma is a stage-independent predictor of survival. J Clin Oncol 30: 1438-1446, 2012.
6. Cross DA, Ashton SE, Ghiorghiu S, Eberlein C, Nebhan CA, Spitzler PJ, Orme JP, Finlay MR, Ward RA, Mellor MJ, et al: AZD9291, an irreversible EGFR TKI, overcomes T790M-mediated resistance to EGFR inhibitors in lung cancer. Cancer Discov 4: 1046-1061, 2014.

7. Wynes MW, Hinz TK, Gao D, Martini M, Marek LA, Ware KE, Edwards MG, Böhm D, Perner S, Helfrich BA, et al: FGFR1 mRNA and protein expression, not gene copy number, predict FGFR TKI sensitivity across all lung cancer histologies. Clin Cancer Res 20: 3299-3309, 2014

8. Laurila $\mathrm{N}$ and Koivunen JP: EGFR inhibitor and chemotherapy combinations for acquired TKI resistance in EGFR-mutant NSCLC models. Med Oncol 32: 205, 2015.

9. Li L, Han R, Xiao H, Lin C, Wang Y, Liu H, Li K, Chen H, Sun F, Yang Z, et al: Metformin sensitizes EGFR-TKI-resistant human lung cancer cells in vitro and in vivo through inhibition of IL-6 signaling and EMT reversal. Clin Cancer Res 20: 27142726, 2014.

10. Su KY, Chen HY, Li KC, Kuo ML, Yang JC, Chan WK, Ho BC, Chang GC, Shih JY, Yu SL, et al: Pretreatment epidermal growth factor receptor (EGFR) T790M mutation predicts shorter EGFR tyrosine kinase inhibitor response duration in patients with non-small-cell lung cancer. J Clin Oncol 30: 433-440, 2012.

11. Miyauchi E, Inoue A, Kobayashi K, Maemondo M, Sugawara S, Oizumi S, Isobe H, Gemma A, Saijo Y, Yoshizawa $\mathrm{H}$, et al; North-East Japan Study Group: Efficacy of chemotherapy after first-line gefitinib therapy in EGFR mutation-positive advanced non-small cell lung cancer-data from a randomized Phase III study comparing gefitinib with carboplatin plus paclitaxel (NEJ002). Jpn J Clin Oncol 45: 670-676, 2015.

12. Kosaka T, Yamaki E, Mogi A and Kuwano H: Mechanisms of resistance to EGFR TKIs and development of a new generation of drugs in non-small-cell lung cancer. J Biomed Biotechnol 2011: $165214,2011$.

13. Yang JJ, Chen HJ, Yan HH, Zhang XC, Zhou Q, Su J, Wang Z, Xu CR, Huang YS, Wang BC, et al: Clinical modes of EGFR tyrosine kinase inhibitor failure and subsequent management in advanced non-small cell lung cancer. Lung Cancer 79: 33-39, 2013.

14. Nurwidya F, Takahashi F, Murakami A and Takahashi K: Epithelial mesenchymal transition in drug resistance and metastasis of lung cancer. Cancer Res Treat 44: 151-156, 2012.

15. Suda K, Tomizawa K, Fujii M, Murakami H, Osada H, Maehara Y, Yatabe Y, Sekido Y and Mitsudomi T: Epithelial to mesenchymal transition in an epidermal growth factor receptor-mutant lung cancer cell line with acquired resistance to erlotinib. J Thorac Oncol 6: 1152-1161, 2011.

16. Stadler SC, Vincent CT, Fedorov VD, Patsialou A, Cherrington BD, Wakshlag JJ, Mohanan S, Zee BM, Zhang X, Garcia BA, et al: Dysregulation of PAD4-mediated citrullination of nuclear GSK $3 \beta$ activates TGF- $\beta$ signaling and induces epithelial-to-mesenchymal transition in breast cancer cells. Proc Natl Acad Sci USA 110: 11851-11856, 2013.

17. Ham A, Rabadi M, Kim M, Brown KM, Ma Z, D'Agati V and Lee HT: Peptidyl arginine deiminase- 4 activation exacerbates kidney ischemia-reperfusion injury. Am J Physiol Renal Physiol 307: F1052-F1062, 2014.

18. Baka Z, Barta P, Losonczy G, Krenács T, Pápay J, Szarka E, Sármay G, Babos F, Magyar A, Géher P, et al: Specific expression of PAD4 and citrullinated proteins in lung cancer is not associated with anti-CCP antibody production. Int Immunol 23: 405-414, 2011.

19. Patki M, Chari V, Sivakumaran S, Gonit M, Trumbly R and Ratnam M: The ETS domain transcription factor ELK1 directs a critical component of growth signaling by the androgen receptor in prostate cancer cells. J Biol Chem 288: 11047-11065, 2013.

20. Senecal A, Munsky B, Proux F, Ly N, Braye FE, Zimmer C, Mueller F and Darzacq X: Transcription factors modulate c-Fos transcriptional bursts. Cell Rep 8: 75-83, 2014.

21. Zhang R, Wang J, Ma S, Huang Z and Zhang G: Requirement of Osteopontin in the migration and protection against Taxol-induced apoptosis via the ATX-LPA axis in SGC7901 cells. BMC Cell Biol 12: 11, 2011.

22. Obacz J, Takacova M, Brychtova V, Dobes P, Pastorekova S, Vojtesek B and Hrstka R: The role of AGR2 and AGR3 in cancer: Similar but not identical. Eur J Cell Biol 94: 139-147, 2015.

23. Bicker KL and Thompson PR: The protein arginine deiminases: Structure, function, inhibition, and disease. Biopolymers 99: 155-163, 2013. 
24. Eades G, Yao Y, Yang M, Zhang Y, Chumsri S and Zhou Q miR-200a regulates SIRT1 expression and epithelial to mesenchymal transition (EMT)-like transformation in mammary epithelial cells. J Biol Chem 286: 25992-26002, 2011.

25. Saitoh M, Shirakihara T and Miyazono K: Regulation of the stability of cell surface E-cadherin by the proteasome. Biochem Biophys Res Commun 381: 560-565, 2009.

26. Cavallaro U, Schaffhauser B and Christofori G: Cadherins and the tumour progression: Is it all in a switch? Cancer Lett 176 : $123-128,2002$

27. Wu Q, Hou X, Xia J, Qian X, Miele L, Sarkar FH and Wang Z: Emerging roles of PDGF-D in EMT progression during tumorigenesis. Cancer Treat Rev 39: 640-646, 2013.

28. Engelman JA, Zejnullahu K, Mitsudomi T, Song Y, Hyland C, Park JO, Lindeman N, Gale CM, Zhao X, Christensen J, et al: MET amplification leads to gefitinib resistance in lung cancer by activating ERBB3 signaling. Science 316: 1039-1043, 2007.

29. Field JK, Oudkerk M, Pedersen JH and Duffy SW: Prospects for population screening and diagnosis of lung cancer. Lancet 382: 732-741, 2013.

30. Xu YH, Mei JS and Zhou J: Randomized study of gefitinib versus pemetrexed as maintenance treatment in patients with advanced glandular non-small cell lung cancer. Int J Clin Exp Med 8: 6242-6246, 2015.

31. Chaft JE, Rekhtman N,Ladanyi M and Riely GJ: ALK-rearranged lung cancer: Adenosquamous lung cancer masquerading as pure squamous carcinoma. J Thorac Oncol 7: 768-769, 2012.

32. Pao W and Girard N: New driver mutations in non-small-cell lung cancer. Lancet Oncol 12: 175-180, 2011.

33. Wagner S, Stuttmann J, Rietz S, Guerois R, Brunstein E, Bautor J, Niefind K and Parker JE: Structural basis for signaling by exclusive EDS1 heteromeric complexes with SAG101 or PAD4 in plant innate immunity. Cell Host Microbe 14: 619-630, 2013.
34. Horn S, Figl A, Rachakonda PS, Fischer C, Sucker A, Gast A, Kadel S, Moll I, Nagore E, Hemminki K, et al: TERT promoter mutations in familial and sporadic melanoma. Science 339: 959-961, 2013

35. Chevigny M, Guérin-Montpetit K, Vargas A, Lefebvre-Lavoie J and Lavoie JP: Contribution of SRF, Elk-1, and myocardin to airway smooth muscle remodeling in heaves, an asthma-like disease of horses. Am J Physiol Lung Cell Mol Physiol 309: L37-L45, 2015.

36. Neeb A, Wallbaum S, Novac N, Dukovic-Schulze S, Scholl I, Schreiber C, Schlag P, Moll J, Stein U and Sleeman JP: The immediate early gene Ier 2 promotes tumor cell motility and metastasis, and predicts poor survival of colorectal cancer patients. Oncogene 31: 3796-3806, 2012.

37. Kawahara T, Shareef HK, Aljarah AK, Ide H, Li Y, Kashiwagi E, Netto GJ, Zheng Y and Miyamoto H: ELK1 is up-regulated by androgen in bladder cancer cells and promotes tumor progression. Oncotarget 6: 29860-29876, 2015.

38. Nieto MA: Epithelial plasticity: A common theme in embryonic and cancer cells. Science 342: 1234850, 2013

39. Rokavec M, Öner MG, Li H, Jackstadt R, Jiang L, Lodygin D, Kaller M, Horst D, Ziegler PK, Schwitalla S, et al: IL-6R/STAT3/miR-34a feedback loop promotes EMT-mediated colorectal cancer invasion and metastasis. J Clin Invest 124: 1853-1867, 2014.

40. Kong D, Li Y, Wang Z and Sarkar FH: Cancer stem cells and epithelial-to-mesenchymal transition (EMT)-phenotypic cells: Are they cousins or twins? Cancers (Basel) 3: 716-729, 2011. 